\title{
A proposal for a classification of neuropathies according to their axonal transport abnormalities
}

\author{
JOHANNES JAKOBSEN, PER SIDENIUS, HANS BRÆNDGAARD
}

From the Diabetes Research Laboratory, Second University Clinic of Internal Medicine, and Department of Neurology, Aarhus Kommunehospital, Aarhus C, Denmark

SUMMARY Recent'studies on axonal transport in experimental neuropathy are reviewed and the following combinations of pathological changes and underlying axonal transport abnormalities are proposed for a classification of polyneuropathies. Alterations of the anterograde transport of slow component $a(S C a)$ leads to changes of the dimensions of the axon calibre without the occurrence either of overt neuropathy or fibre loss. Thus damming of $\mathrm{SCa}$ in $\beta, \beta^{\prime}$-iminodiproprionitrile (IDPN) intoxication results in axonal swelling in nerve roots whereas decrease of SCa leads to atrophy distal to the swellings in IDPN intoxication and in streptozotocin induced diabetes as well. Decrease in the amount of material conveyed within the anterograde fast component ( $a F C$ ) leads to acute axonal degeneration including break down of axons and fibre loss. This state occurs in acute hypoglycaemia and in doxorubicin intoxication. The most frequent type of polyneuropathy, namely distal axonopathy with accumulation of axon organelles leading to distal fibre loss, is associated with decrease in amount of the retrograde fast component ( $r F C)$. The transport is impaired before the appearance of symptoms and electrophysiological signs of neuropathy develop in the intoxications induced by parabromophenylacetylurea, acrylamide and 2.5 hexanedione, and the severity of neuropathy is proportional to the rFC impairment.

Although improvement in diagnosis of peripheral neuropathies has been achieved during recent years these conditions are still poorly distinguished. Diagnosis relies on symptoms, neurological signs, neurophysiological and chemical findings, and in some cases biopsy studies. Most classifications are based on histological criteria; the latest distinguishes between four categories of neuropathies, namely neuronopathies, proximal axonopathies, distal axonopathies, and myelinopathies. ${ }^{1}$ These categories, however, are not aetiological but merely a description of pathological changes that result from a variety of causes. In fact, demyelination can occur secondary to axonal atrophy ${ }^{2}$ and the same neurotoxic compound can produce more than one neuronal reaction depending on dosage. ${ }^{34}$

It is not possible yet to group the neuropathies

Address for reprint requests: Dr J Jakobsen, Department of Neurology, Aarhus Kommunehospital, DK-8000, Aarhus C, Denmark.

Received 10 January 1986

Accepted 3 February 1986 according to biochemical criteria related to disease mechanisms, nor does this goal appear to be achievable in the near future. In the meantime, we propose a new classification based on axonal transport abnormalities combined with structural alterations. In our opinion, the inclusion of alterations in axon function provides new insight in the pathogenesis of these conditions.

\section{The axonal transport system}

Studies by Ochs et al during the sixties established the existence of the axonal transport system and clarified the dependence of the fast anterograde component on oxidative phosphorylation. ${ }^{56}$ Later the anterograde slow components and the retrograde fast component were described. Ultrastructural and gelelectrophoretic studies by the groups of Lasek and Willard have made it clear that each component of the transport system is identical with a specific axonal organelle (table 1). ${ }^{7-9}$ The pathological consequence of this structural hypothesis on axonal transport is that impairment of the various transport components 
Table 1 Axonal organelles, their corresponding components of the axonal transport system, and some of their physical and chemical characteristics

\begin{tabular}{|c|c|c|c|}
\hline Axonal organelle & Transport component & Transport velocity & Molecular constituents \\
\hline Neurofilaments & Slow component a (SCa) group V & $1 \mathrm{~mm} / \mathrm{d}$ & $\begin{array}{l}\text { Triplet of neurofilament proteins ( } 200 \text {, } \\
145 \text {, and } 68 \mathrm{kdalton})\end{array}$ \\
\hline Neurotubules & $\mathrm{SCa} / \mathrm{SCb}$ & $2 \mathrm{~mm} / \mathrm{d}$ & $\alpha$-tubulin, $\beta$-tubulin \\
\hline Microfilament network & Slow component b (SCb) group IV & $4 \mathrm{~mm} / \mathrm{d}$ & $\begin{array}{l}\text { Actin, calmodulin, fodrin, enzymes } \\
\text { of intermediary metabolism etc. }\end{array}$ \\
\hline Mitochondria & Group II & $50 \mathrm{~mm} / \mathrm{d}$ & Mitochrondrial enzymes \\
\hline $\begin{array}{l}\text { Vesicles, smooth endoplasmic } \\
\text { reticulum }\end{array}$ & $\begin{array}{l}\text { Anterograde fast component (aFC), } \\
\text { group I }\end{array}$ & $400 \mathrm{~mm} / \mathrm{d}$ & $\begin{array}{l}\text { Glycoproteins, lipids, transmitters, } \\
\mathrm{Na} / \mathrm{K}-\mathrm{ATPase} \text { etc. }\end{array}$ \\
\hline $\begin{array}{l}\text { Secondary lysosomes, } \\
\text { multivesicular bodies }\end{array}$ & Retrograde fast component (rFC) & $200 \mathrm{~mm} / \mathrm{d}$ & Similar to aFC \\
\hline
\end{tabular}

should be associated with different structural alterations.

Experimental studies on axonal transport in toxic and metabolic neuropathies in animal models have so far revealed a variety of changes. In our laboratory, we have examined various experimental conditions in an attempt to recognise patterns of transport abnormalities as well as their relation to neuropathology. ${ }^{10}$ We now suggest that three distinct categories of axonal transport abnormalities can be distinguished and related to separate types of nerve pathology.

\section{Impairment of the axonal transport of the anterograde slow component a ( $\mathrm{SCa})$}

The anterograde slow components consist of three parts of the cytoskeleton: neurofilaments, neurotubules, and the microfilament network. ${ }^{8}$ Chemically the neurofilaments ( $\mathrm{SCa}$ ), are made up of the so-called neurofilament triplet $(200,145$, and $68 \mathrm{kdal}-$ ton). ${ }^{7}$ The transport velocity of this component in the normal organism is about $1 \mathrm{~mm} / \mathrm{d}$. Changes in the transport of neurotubules and microfilaments have not been described and these components will not be mentioned further.

Griffin and his colleagues were the first to suggest that changes in the transport of neurofilaments were related to structural axonal alterations. These authors studied the $\beta, \beta^{\prime}$-iminodipropionitrile (IDPN) neuropathy and found that swellings of the proximal parts of the axon were due to a retention of neurofilaments. ${ }^{11}$ Later they showed that distal to the swellings, the neurofilament transport was decreased and atrophy of the axon took place. ${ }^{12}$ Similar findings have been made after intoxication with aluminium and 3,4-dimethyl-2,5-hexandione (DMHD) ${ }^{1314}$ In accordance with these findings quantitative electronmicroscopic studies show a close correlation between the number of neurofilaments (and neurotubules) and axon calibre in normal axons. ${ }^{15}$

In experimental diabetes a reduction in the transport velocity of slow component a (SCa) and axonal dwindling were found. ${ }^{16-19}$ Furthermore, we observed that in this condition the amount of material transported was reduced. ${ }^{20}$ Recently, gelelectrophoretic studies showed a corresponding decreased transport velocity of two neurofilament subunits in diabetic mice. ${ }^{21} \mathrm{~A}$ decreased transport velocity of $\mathrm{SCa}$ and a decrease of fibre calibre are also seen in rats after galactose feeding as well as after administration of BPAU. ${ }^{22-25}$ Assuming that the transport of SCa is a transport of neurofilaments, this means that axonal atrophy is caused by a decrease of this transport. This conclusion has further been corroborated by the observation that temporary decreases of neurofilament transport induced by acrylamide are followed by temporary reductions of axonal calibre. ${ }^{4}$

In summary, here we have two pathological reactions related to changes in neurofilament transport. At the site of damming of transport a swelling of the axon arises while a decrease of transport leads to axonal atrophy.

Impairment of the axonal transport of the anterograde fast component (aFC)

The anterograde fast component (aFC) consists of membranous material and is presumably transported in the form of vesicles and smooth endoplasmic reticulum. ${ }^{26}$ The transport velocity is about $400 \mathrm{~mm} / \mathrm{d}$ and among the many substances contained in the component are transmitters and their enzymes, $\mathrm{Na} / \mathrm{K}$-ATPase and many other uncharacterised proteins. ${ }^{5}$ It is assumed that the vesicles are incorporated into the axolemma and the nerve endings and, thus, are necessary for the renewal of the cell membrane of the axon. Therefore, impairment of this component most likely will have rapid and disastrous consequences to the integrity of the axon all along its course.

Ochs suggested several years ago that the transport velocity of this system would be unaffected in all conditions, ${ }^{5}$ as he considered the ATP-dependent mechanism to be an all or none response. We have demonstrated that this holds true as regards experimental 
diabetes, ${ }^{27}$ as well as intoxication with p-bromophenyl-acetylurea (BPAU), ${ }^{24}$ acrylamide, ${ }^{28}$ doxorubicin $^{29}$ and 2,5-hexanedione (2,5-HD). ${ }^{30}$ In all these conditions transport velocity of aFC remains unchanged.

Glucose is the main fuel for peripheral nerve energy metabolism ${ }^{31}$ and the aFC, therefore, most likely is dependent on the presence of glucose. We have shown that insulin induced hypoglycaemia can lead to acute axonal degeneration with breakdown of axon structure and to characteristic alterations in the cell bodies. ${ }^{32}$ Recently, we studied the transport during insulin induced hypoglycaemia. ${ }^{33}$ Acute lowering of blood glucose leads to reduction in the amount of material in transport whereas velocity is unchanged.

Doxorubicin, a cytostatic agent, interferes with protein metabolism in sensory nerve cell bodies. The neuropathy produced by doxorubicin is characterised by an acute axonal degeneration like the one described in hypoglycaemia (to be published). Again the abnormality in axonal transport is a reduction in the amount of material carried by aFC. ${ }^{29}$

Though quantitative studies are wanting, colchicine and vincristine are known to impair the fast axonal transport by disruption of the microtubules leaving the slow axonal transport unaffected. ${ }^{34}$ In human beings as well as in animals axonal degeneration equally distributed along the nerve is associated with the condition. ${ }^{35} 36$

If a nerve fibre is transected, the axon distal to the interruption undergoes Wallerian degeneration with acute fibre breakdown. The loss of axonal continuity deprives the distal part of the axon of all anterograde components of axonal transport, including SCa. Following the depletion of aFC transport in the isolated distal segment, the amount of material available for retrograde transport is also decreased. Neither reduction in SCa nor in retrograde transport, however, are associated with acute axonal degeneration. Thus, decrease in protein synthesis, decrease in energy level, and mechanical interruption of axon structure are all capable of producing failure in delivery of material by the fast anterograde transport system and are all associated with degeneration of the acute type.

We, therefore, suggest that the pathological reaction to a decrease in aFC is the acute axonal fibre breakdown of the Wallerian type.

\section{Impairment of the axonal transport of the retrograde fast component ( $r F C$ )}

The retrograde fast component ( $\mathrm{rFC}$ ) consists of proteins with a molecular composition very similar to the one of aFC. ${ }^{37}$ The retrogradely transported material is located in multivesicular bodies, the secondary lysosomes. ${ }^{26}$ Transport velocity is about $200 \mathrm{~mm} / \mathrm{d}$ and the transport mechanism seems similar to the one of aFC. ${ }^{5}$

It is generally assumed that the retrograde transport can be estimated from the accumulation of material distal to a nerve crush within the first $24 \mathrm{~h}$ following fibre interruption. The neuropathies induced by zinc pyridinethione (ZPT), ${ }^{38}$ BPAU, ${ }^{39}$ acrylamide, ${ }^{40}$ and $2,5-\mathrm{HD}^{41}$ are all characterised as distal axonopathies and the development of symptoms or histological signs takes several days or weeks. In all these toxic conditions the most prominent axonal transport abnormality is by far-a reduction of distal accumulation of retogradely transported material. ${ }^{244042-47}$

The structural changes of distal axonopathies have not been characterised quantitatively. Preterminal swellings have been observed but it is unknown whether they are primary changes or whether they occur secondarily to loss of the nerve endings. In fact, Mendell and Sahenk cautiously interpreted their findings of a decrease in $\mathrm{rFC}$ after administration of ZPT, acrylamide, and 2,5-HD as a secondary phenomenon caused by structural alterations in the nerve endings. ${ }^{44}$

In the BPAU neuropathy, however, reduced distal accumulation is present as early as two days after a single dose is given whereas signs of neuropathy appear several days later ${ }^{24}$ Furthermore, the amount of reduction of rFC in disabled animals is closely related to neurophysiological estimates of the degree

Table 2 Type and causations of peripheral neuropathy in animal models and the associated abnormalities of the axonal transport system

\begin{tabular}{|c|c|c|}
\hline Axonal transport alteration & Structural consequence & Condition \\
\hline SCa, impairment & Axonal atrophy/swelling & $\begin{array}{l}\beta, \beta^{\prime} \text {-iminodipropionitrile (IDPN), aluminum, } \\
\text { 3,4-dimethyl-2,5-hexanedione (DMHD) } \\
\text { experimental diabetes, p-bromophenylacetylurea (BPAU), } \\
\text { doxorubicin }\end{array}$ \\
\hline & Acute fibre breakdown & $\begin{array}{l}\text { Hypoglycaemia, doxorubicin, colchicine, vincristine, Wallerian } \\
\text { degeneration }\end{array}$ \\
\hline rFC, decrease of amount & Distal axonopathy & $\begin{array}{l}\text { Acrylamide, 2,5-hexanedione (2,5-HD), BPAU, zinc } \\
\text { pyridinethione (ZPT), (experimental diabetes) }\end{array}$ \\
\hline Intact transport & $\begin{array}{l}\text { Myelinopathy or electrophysiological } \\
\text { disturbance }\end{array}$ & Diphtheria toxin, tetrodotoxin etc. \\
\hline
\end{tabular}


of paresis. ${ }^{48}$ In acrylamide neuropathy, the defect in rFC occurs before signs of neuropathy appear and is closely related to the dosage ${ }^{44}$ and the retrograde defect in accumulation cannot be produced by related substances unable to produce neuropathy. ${ }^{44}$ In 2,5-HD intoxication motor functions are more affected than the sensory system and so is the rFC in motor as compared with sensory nerves. ${ }^{47}$ Again the defect is related to dosage and present before neuropathy is apparent.

There is more than one possible explanation of the impairment of retrograde axonal transport. It could be due to a decreased retrograde transport capacity or to a decreased amount of material available for transport in the nerve endings. The latter possibility could occur either as the result of breakdown of aFC in the most distal part of the axon or, more likely, as the result of a defect in the turn-around process.

Whatever the exact mechanism of the impairment of $\mathrm{rFC}$ is, it is obvious that this transport abnormality is closely related to the neuropathic condition of the distal axonopathies including withering away of terminals and preterminal swellings with accumulation of vesicular elements and filaments.

\section{Neuropathies without axonal transport abnormalities}

As an important corollary of our hypothesis that structural axon changes are mediated by changes in axonal transport, we postulate that if the various components of the axon transport system are unaffected in a neuropathic condition, no structural changes in the axon will be found. Consequently, the neuropathy must either be a myelinopathy or an electrophysiological disturbance.

\section{Conclusion}

We suggest that incorporation of the abnormalities of axonal transport in the classification of the different types of nerve pathology is justified by the predictable patterns of transport changes occurring in the various neuropathies. As mentioned above (table 2) three different types of axonal transport abnormalities are now recognised experimentally, namely impairment of $\mathrm{aFC}$ and $\mathrm{rFC}$ and damming or decrease of $\mathrm{SCa}$.

If this conclusion is valid then in the human condition, distal atrophy due to damming of neurofilament transport might underlie some of the inherited neuropathies; axonal dwindling caused by a decreased neurofilament transport might be seen in early diabetes mellitus; acute axonal degeneration with impairment of aFC might occur in porphyric neuropathy and in hypoglycaemia; while distal axonopathy with a decrease in amount of retrograde axonal transport could represent the type of neuropathy most commonly met after exposure to neurotoxic substances.

\section{References}

${ }^{1}$ Spencer PS, Schaumburg HH. Classification of neurotoxic disease: a morphological approach. In: Spencer PS, Schaumburg HH, eds. Experimental and Clinical Neurotoxicology. Baltimore/London: William \& Wilkins, 1980:92-9.

${ }^{2}$ Dyck PJ, Johnson WJ, Lambert EH, O'Brien PC. Segmental demyelination secondary to axonal degeneration in uremic neuropathy. Mayo Clin Proc 1971; 46:400-31.

${ }^{3}$ Griffin JW, Gold BG, Cork LC, Price DL, Lowndes HE. IDPN neuropathy in the cat. Coexistence of proximal and distal axonal swellings. Neuropathol Appl Neurobiol 1982;8:351-64.

${ }^{4}$ Gold BG, Griffin JW, Price DL. Slow axonal transport in acrylamide neuropathy: different abnormalities produced by single-dose and continuous administration. $J$ Neurosci 1985;5:1755-68.

${ }^{5}$ Ochs S. Basic properties of axoplasmic transport. In: Dyck PJ, Thomas PK, Lambert EH, Bunge R, eds. Peripheral Neuropathy. Philadelphia: WB Saunders Company, 1984:453-76.

${ }^{6}$ Ochs S, Hollingworth D. Dependence of fast axoplasmic transport in nerve on oxidative metabolism. $J$ Neurochem 1971;18:107-14.

${ }^{7}$ Hoffman PN, Lasek RJ. The slow component of axonal transport. Identification of major structural polypeptides of the axon and their generality among mammalian neurons. J Cell Biol 1975;66:351-66.

${ }^{8}$ Tytell M, Black MM, Garner JA, Lasek RJ. Axonal transport: each major rate component reflects the movement of distinct macromolecular complexes. Science 1981;214:179-81.

${ }^{9}$ Willard MB, Hulebak KL. The intra-axonal transport of polypeptide $\mathrm{H}$ : evidence for a fifth (very slow) group of transported proteins in the retinal ganglion cells of the rabbit. Brain Res 1977;136:289-306.

${ }^{10}$ Jakobsen J, Sidenius P. Axonal transport in experiemental diabetes and other models of metabolic and toxic neuropathies. In: Iqbal $\mathrm{Z}$, ed. Axoplasmic Transport. Cleveland: CRC Press, Inc., 1986: in press.

${ }^{11}$ Griffin JW, Hoffman PN, Clark AW, Carroll PT, Price DL. Slow axonal transport of neurofilament proteins: impairment by $\beta, \beta$-iminodipropionitrile administration. Science 1978;202:633-5.

${ }^{12}$ Clark AW, Griffin JW, Price DL. The axonal pathology in chronic IDPN intoxication. J Neuropathol Exp Neurol 1980;39:42-55.

${ }^{13}$ Bizzi A, Crane RC, Autilio-Gambetti L, Gambetti P. Aluminum effect on slow axonal transport: a novel impairment of neurofilament transport. $J$ Neurosci 1984;4:722-31.

${ }^{14}$ Griffin JW, Anthony DC, Fahnestock KE, Hoffman PN, Graham DG. 3,4-dimethyl-2,5-hexanedione impairs the axonal transport of neurofilament proteins. $J$ Neurosci 1984;4:1516-26.

${ }^{15}$ Friede RL, Samorajski T. Axon caliber related to neurofilaments and microtubules in sciatic nerve fibers of rats and mice. Anat Rec 1970;167:379-88.

${ }^{16}$ Jakobsen J, Sidenius P. Decreased axonal transport of structural proteins in streptozotocin diabetic rats. J Clin 
Invest 1980;66:292-7.

${ }^{17}$ Jakobsen J. Axonal dwindling in early experimental diabetes. I. A study of cross sectioned nerves. Diabetologia 1976;12:539-46.

${ }^{18}$ Jakobsen J. Early and preventable changes of peripheral nerve structure and function in insulin-deficient diabetic rats. J Neurol Neurosurg Psychiatry 1979;42:509-18

${ }^{19}$ Sharma AK, Bajada S, Thomas PK. Influence of streptozotocin-induced diabetes on myelinated nerve fibre maturation and on body growth in the rat. Acta Neuropathol (Berl) 1981;53:257-65.

${ }^{20}$ Sidenius $\mathbf{P}$, Jakobsen J. Reversibility and preventability of the decrease in slow axonal transport velocity in experimental diabetes. Diabetes 1982;31:689-93.

${ }^{21}$ Vitadello M, Filliatreau G, Gupont JL, Hassig R, Gorio A, Di Giamberardino L. Altered axonal transport of cytoskeletal proteins in the mutant diabetic mouse. $J$ Neurochem 1985;45:860-8.

${ }^{22}$ Sidenius P, Jakobsen J. Axonal transport in rats after galactose feeding. Diabetologia 1980;19:229-33.

${ }^{23}$ Sharma AK, Thomas PK, Baker RWR. Peripheral nerve abnormalities related to galactose administration in rats. J Neurol Neurosurg Psychiatry 1976;39:794-802.

${ }^{24}$ Jakobsen J, Brimijoin S. Axonal transport of enzymes and labelled proteins in experimental axonopathy induced by p-bromophenylacetylurea. Brain Res 1981;229: 103-23.

${ }^{25}$ Ohnishi A, Ikeda M. Morphometric evaluation of primary sensory neurons in experimental p-bromophenylacetylurea intoxication. Acta Neuropathol (Berl) 1980;52:111-18.

${ }^{26}$ Tsukita $S$, Ishikawa $H$. The movement of membranous organelles in axons. Electron microscopic identification of anterogradely and retrogradely transported organelles. J Cell Biol 1980;84:513-30.

${ }^{27}$ Sidenius P, Jakobsen J. Axonal transport in early experimental diabetes. Brain Res 1979;173:315-30.

${ }^{28}$ Sidenius P, Jakobsen J. Anterograde axonal transport in rats during intoxication with acrylamide. $J$ Neurochem 1983;40:697-704.

${ }^{29}$ Sidenius P. The effect of doxorubicin on slow and fast components of the axonal transport system in rats. Brain 1986: accepted for publication.

${ }^{30}$ Brændgaard $\mathrm{H}$, Sidenius $\mathrm{P}$. The anterograde components of axonal transport in motor and sensory nerves in experimental 2,5-hexanedione neuropathy. J Neurochem 1986: in press.

${ }^{31}$ Greene DA, Winegrad AI. In vitro studies of the substrates for energy production and the effects of insulin on glucose utilization in the neural components of peripheral nerve. Diabetes 1979;28:878-87.

${ }^{32}$ Sidenius P, Jakobsen J. Peripheral neuropathy in rats induced by insulin treatment. Diabetes 1983;32:383-6.

${ }^{33}$ Cho ES, Spencer PS, Jortner BS, Schaumburg HH. A single intravenous injection of doxorubicin (adriamycin) induces sensory neuronopathy in rats. Neurotoxicology 1980;1:583-91.

${ }^{34}$ Bradley WG, Williams MH. Axoplasmic flow in axonal neuropathies. I. Axoplasmic flow in cats with toxic neuropathies. Brain 1973;96:235-46.

${ }^{35}$ Bradley WG, Lassman LP, Pearce GW, Walton JN. The neuromyopathy of vincristine in man. Clinical, electrophysiological and pathological studies. J Neurol Sci 1970;10:107-31.

${ }^{36}$ Bradley WG. The neuromyopathy of vincristine in the guinea pig. An electrophysiological and pathological study. J Neurol Sci 1970;10:133-62.

${ }^{37}$ Abe T, Haga T, Kurokawa M. Retrograde axoplasmic transport: its continuation as anterograde transport FEBS Lett 1974;47:272-5.

${ }^{38}$ Sahenk Z, Mendell JR. Ultrastructural study of zinc pyridine-thione-induced peripheral neuropathy. $J \mathrm{Neu}$ ropathol Exp Neurol 1979;38:532-50.

${ }^{39}$ Cavanagh JB, Chen FCK, Kyu MH, Ridley A. The experimental neuropathy in rats caused by $p$ bromophenylacetylurea. J Neurol Neurosurg Psychiatry 1968;31:471-8.

${ }^{40}$ Prineas J. The pathogenesis of dying-back polyneuropathies. Part II. An ultrastructural study of experimental acrylamide intoxication in the cat. $J \mathrm{Neu}$ ropathol Exp Neurol 1969;28:598-621.

${ }^{41}$ Spencer PS, Schaumburg HH. Experimental neuropathy produced by 2,5-hexanedione - a major metabolite of the neurotoxic industraial solvent methyl n-butyl ketone. J Neurol Neurosurg Psychiatry 1975;38:771-5.

${ }^{42}$ Sahenk Z, Mendell JR. Axoplasmic transport in zinc pyridine-thione neuropathy: evidence for an abnormality in distal turn-around. Brain Res 1980;186:343-53

${ }^{43}$ Sahenk Z, Mendell JR. Acrylamide and 2,5-hexandione neuropathies: abnormal bidirectional transport rate in distal axons. Brain Res 1981;219:397-405.

44 Jakobsen J, Sidenius P. Early and dose-dependent decrease of retrograde axonal transport in acrylamideintoxicated rats. $J$ Neurochem 1983;40:447-54.

${ }^{45}$ Miller MS, Miller MJ, Burks TF, Sipes IG. Altered retrograde axonal transport of nerve growth factor after single and repeated doses of acrylamide in the rat. Toxicol Appl Pharmacol 1983;69:96-101.

${ }^{46}$ Miller MS, Spencer PS. Single doses of acrylamide reduce retrograde transport velocity. $J$ Neurochem 1984; 40:1401-8.

${ }^{47}$ Brændgaard $\mathrm{H}$, Sidenius $\mathrm{P}$. The retrograde fast component of axonal transport in motor and sensory nerves of rat during administration of 2,5-hexanedione. Brain Res 1986: in press.

${ }^{48}$ Brimijoin S, Dyck PJ, Jakobsen J, Lambert EH. Axonal transport in human nerve disease and in the experimental neuropathy induced by p-bromophenylacetylurea. In: Weiss D, Gorio A, eds. Axoplasmic Transport. New York: Raven Press, 1982:124-30. 